has certainly the drawback that, as it leaves the patient perfectly conscious of all the preparations for the procedure which he dreads, nervous people suffer under its use nearly all the terror which they would without an anæsthetic; and this terror is perhaps the most painful part of these trifling operations. I cannot help thinking that the limited extent to which a method so easy, so free from danger, and so confessedly effective in these minor operations, has been adopted, is a proof that the profession at large have come to a different conclusion as to the dangers of the plan it was intended to supersede, from that adopted by its ingenious author.

I must now bring these observations to a close. My object in them has been to show what the mortality after chloroform has really been, and to inquire whether the results of post mortem examination have given us any clue for assigning it to its efficient cause. In reference to these two points, I believe the facts before us show-

1. That the reported mortality in the British Islands has been less than six per annum; that a great number of these casies occurred in private practice; and that, as many of them were disclosed by means of coroners' inquests, it seems probable that we do really hear of most of the fatal cases which occur in the United Kingdom.

2. That the post mortem appearances have not been suffi. cient to indicate any uniform cause of death; that the im. portance ascribed usually to fatty degeneration of the heart is greater than experience would warrant; that, from the number of cases of persons previously in perfect health, and the rapidity with which death was produced, there is a strong presumption that the result was due to imperfect methods of administration, or carelessriess on the part of the administrator. Further, from the experience of hospitals in which a rational method has been adopted and due caution exercised, we are jnstified in believing that chloroform is as safe in its action as any drug which produces narcotism by mixing with the circulating blood, can in the nature of things be expected to be.

4 , Vigo Street, February 1857 .

\section{CLINICAL OBSERVATIONS ON THE TREATMENT OF FRACTURES BY THE IMMOVABLE APPARATUS.}

By Joseph Sampson Gamgee, Staff-Surgeon of the first class, and Principal Medical Officer of the British Italian Legion during the last war; late Assistant-Surgeon to the Royal Free Hospital, etc.

"Pereaps there is no subject more interesting to the practical surgeon than this of fracture of the limbs.... This is one of those subjects which has fallen into almost inextricable confusion: none, I believe, requires more to be historically explained.... It is, I fear, but too certain, that, while more has been written on the subject of fractures than on hernia, lithotomy, amputation, or trepan, yet no two books correspond, no two authors agree, even on the general points of practice; and every surgeon, whether in the army or in the navy, in a village or in a city, sets a broken limb, as he writes his name, after a fashion of his own." (John Bell's Principles of Surgery, pp. 490-1. London, 1815.)

This is not the first time I quote* the above passage from the eloquent chirurgic treatise of John Bell; -a passage so pregnant with truth of the greatest practical moment; that instead of apologising for repeatedly referring to it, I would recommend its insertion in the commonplace-book of every diligent seeker after truth. Fractures are the surgery of every surgeon's every day. They often involve the life, always the comfort, of the large number of individuals who are afflicted with them; they are a department of practice in which the very greatest manual dexterity is often called for, without such opportunity for display as is afforded by cases in which cutting instruments are employed; and it is to be feared that not sufficient importance is attached to their study, in the period more especially allotted for acquiring a fundamental knowledge of practical surgery. The large amount of valuable experience which might be collected from the fractures in our out-patients' rooms, is but very inadequately availed of, while any one "walking the hospitals" must be struck by the fact that house surgeons and dressers, but more especially the former, monopolise the learning to be

- Chapter on the Relative Merits of the different Methods of Treating Frictures of the Lower Limbs, at p. 134 et seq. of "Researches in Patholo. gieal Anatomy and Clinical Surgery," by Joweph Bmapson Onesoo, with aix derived from fractures admitted into the wards. At the surgeon's visits, the limb is seen "done up," and in due course, the amount of information acquired by the majority of students is, that A. B. was admitted such a day with a fracture, ob lique or otherwise, with shortening, reduction effected, apparatus applied, and patient discharged with the result witnessed, be it good or bad. Supposing the case to have been one of oblique fracture through the trochanters, above the femoral condyles, or through both bones in the small of the leg, how many times during the progress of the cases has there been cause for anxiety, and call for the nicest manual dexterity! How much has depended on the surgeon's head and hands, altogether apart from the merits inherent to the apparatus adopted!

My desire is to be brief; and yet I have been obliged to sub. mit these introductory general reflections, from a conviction that the considerations of cases and principles into which we are about to enter would be comparatively valueless, unless it were borne in mind how essentially this subject is one of practical importance, admitting only of solution on the basis of experience, acquired, as experience to be valuable must be, by the exclusion of all prejudice, by a clear and accurate apprecia tion of facts, and by an appropriate use of the ambassadors and agents of the understanding - the hands.

I reflect with satisfaction that my first publication on this subject was concluded in the following terms:* "That th system I advocate does possess real advantages in a large number of cases, can no longer be matter of doubt. Whether or not all my anticipations respecting it admit of realisation, is a question well deserving future clinical observation for its solution." The subject was one which had been so complicated by vague assertion and practical inconsistencies, that I determined it should not, for my part, be further imperilled by partial observation or illogical argument. I had leårned from the immortal genius in and for whose memory my little treatise had been prepared, that "years are not the measure of experience; that it does not follow, that the older the surgeon is, the more experienced and trustworthy he must be; that it is the greatest number of well assorted facts on a particular subject which constitutes experience, whether those facts have been culled in five years or in fifty." + It will, I trust, appear from a perusal of the serial communications now prefaced, that faith has been kept with the great master's teaching; and I shall not hesitate even to seem tedious in minutely analysing every particular which can exercise even the most remote influence on the demonstrative truth of tenets which are to form a code of experience. The question is one of fact, and by fact it must be solved.

Necessitating, as do the facts which I have to contribute, some knowledge of the plan under discussion, I beg to refer the readers of this Journax to its volume for 1855 , for a series of papers on the Treatment of Fractures by Mr. Benjamin Hunt of Birmingham. Those papers are in my opinion some of the most valuable contributions to periodical surgical literature; and since it is the fate of memoirs in journals to become buried with time, the present communication will at least have had the effect of again directing attention to a series of clinical facts, which have not been studied and put to the test of experience in proportion to their weight.

[To be continued.]

16, Upper Woburn Place, Russell Square, February 18th, 1857.

SALE OF Porsons. Last week a servant-of-all-work, named Anne Boxall, resident in the house of Mrs. Adams at Peters. field, committed suicide by taking a dose of "mouse powder" (Battle's "vermin-killer"), which contains the deadly drug strychnine. It was purchased by a fellow-servant at a drug gist's shop. The doctor found the wretched girl in a state of spasm. On endeavouring to raise her head (to which she strongly objected), in order to introduce the tube of the stomach-pump, he found it impossible to force open her mouth. She repeatedly expressed a wish to have her legs rubbed, and also her feet. He was about to use; chloroform, when she expired in great pain. The stomach was found to be very much inflamed, and showed the results of an active poison. (Sussex Express.)

* "On the Advantages of the Starched Apparatus in the Treatment of Fractures and Diseases of Joints," being the Liston Prize Essay for 1853, by Joseph Sampson Gamgee,

+ "Elements of Surgery," by Robent Liston. Second odition. Londox, 1840. Prefence, p. vi. 